\title{
Penerapan Alat Permainan Edukatif Bertemakan Keselamatan Lalulintas Untuk Guru TK Karya Bunda Kec.Bandar Seikijang
}

\author{
Alfian Saleh*1, Muthia Anggraini' $^{2}$, Sean Marta Efastri ${ }^{3}$ \\ 1,2Program Studi Teknik Sipil, Fakultas Teknik Universitas Lancang Kuning, \\ ${ }^{3}$ Program Studi PG PAUD, FKIP, Universitas Lancang Kuning

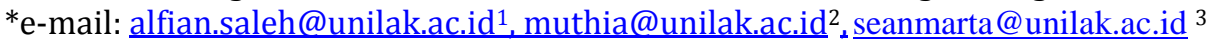

\begin{abstract}
Kindergarten located in Bandar Seikijang District which is on the edge of the eastern causeway which is an accident-prone road. In addition, there is no curriculum related to traffic safety in the learning process. In overcoming partner problems, the service team provides solutions to partners in the form of assistance in making traffic safety educational tools that are applied to the curriculum in schools. The purpose of this activity is to improve the ability of teachers in making traffic safety props so that later the teachers can apply them to kindergarten students in their schools. There are four steps for implementing (1) the preparation stage, (2) the activity stage, (3) the simulation stage, (4) the evaluation stage. From the results obtained, 100\% of teachers understand the importance of safety for their students. This activity provides benefits to hone the skills of teachers in the teaching and learning process by applying this educational game tool.
\end{abstract}

Keywords: Safety, The Educational Game Tool

\begin{abstract}
Abstrak
TK Karya Bunda yang berada di Kecamatan Bandar Seikijang yang berada di pinggir jalan lintas timur yang merupakan jalan rawan kecelakaan. Selain itu juga kurikulum yang berhubungan dengan keselamatan berlalu lintas belum ada dibuat dalam proses pembelajaran. Dalam mengatasi permasalahan mitra maka tim pengabdian memberikan solusi berupa pendampingan dalam pembuatan alat permainan edukatif keselamatan berlalu lintas yang diterapkan pada kurikulum di sekolah. Langkah-langkah pelaksanaan solusi yang ditawarkan dalam mengatasi permasalahan tersebut yaitu ada empat tahap yaitu (1) tahap persiapan, (2) tahap kegiatan, (3) tahap simulasi, (4) tahap evaluasi. Dari hasil yang didapat 100\% guru memahami arti penting keselamatan untuk siswanya. Kegiatan ini memberikan manfaat untuk mengasah kemampuan guru dalam proses belajar mengajar dengan penerapan alat permainan edukatif ini.
\end{abstract}

Kata kunci: Alat Permainan Edukatif (APE), Keselamatan Lalulintas

\section{PENDAHULUAN}

Kecamatan Bandar Seikijang merupakan salah satu kecamatan yang berada di Kabupaten Pelalawan yang sebagian besar wilayahnya dilintasi oleh jalan lintas timur sumatera. Akses jalan Lintas Timur Sumatera ini merupakan jalan yang menghubungkan Kota Pekanbaru dengan Kabupaten Pelalawan. Jalan lintas timur ini banyak dilalui oleh kendaraan mulai dari kendaraan berat, kendaraan sedang, kendaraan ringan dan sepeda motor. Jalan ini merupakan daerah rawan kecelakaan. Selain itu juga ada beberapa sekolah yang persis berada di pinggir jalan tersebut salah satunya adalah TK Karya Bunda. Dari hasil survey lapangan kondisi geografis TK tersebut sangat minim dengan rambu keselamatan dan juga berada persis di tikungan sehingga titik tersebut sangat berpotensi terjadinya kecelakaan.

TK menurut PP RI No. 27 Tahun 1990 tentang Pendidikan Prasekolah Bab 1 pasal 1 ayat 2 adalah salah bentuk Pendidikan Prasekolah yang menyediakan program pendidikan dini bagi anak usia empat tahun sampai memasuki pendidikan dasar. Seorang guru merupakan ujung tombak anak didiknya dalam meningkatkan kualitas pendidikan. Guru TK sangat berperan penting karena disini seorang guru TK mendidik seorang anak yang memiliki cara berfikir yang berbeda dengan orang dewasa. Guru TK harus membentuk karaktek anak agar mereka memiliki pondasi akhlak dan karakter yang kuat kelaknya. Seperti halnya karaktek dalam sadar akan keselamatn barlalu lintas, harus ditanamkan sejak dini sehingga setelah dewasa masih melekat dibenaknya untuk sadar akan berlalu lintas. Dalam hal ini seorang anak khususnya anak TK, yang 
berfikir berdasarkan pengalaman dan benda-benda yang dilihat atau benda konkret setidaknya dapat mengingatkan orang tuanya akan pentingnya keselamatan berlalu lintas.

Berdasarkan wawancara kami dengan Ibu Jamilah yaitu Kepala Sekolah TK Karya Bunda, beliau mengatakan guru - guru TK Karya Bunda hanya berjumlah 5 orang guru satu orang sudah memiliki gelar sarjana PAUD selebihnya hanya tamat SMA, D1, D2 dan D3. Minimnya SDM yang dimiliki merupakan salah satu faktor mereka dalam hal meningkatkan kompetensi pengembangan pembelajaran salah satunya yang berkaitan dengan pembelajaran keselamatan berlalu lintas. Mereka menyadari bahwa lingkungan sekolah yang berada di jalur lintas timur, sehingga perlu dilakukan pengenalan keselamatan berlalu lintas untuk anak-anak. Selama ini pembelajaran itu belum ada diajarkan ke anak - anak, karena belum ada memiliki alat peraga edukatif.

Menurut Undang - Undang Guru dan Dosen Nomor 14 Tahun 2005 pasal 8 menyatakan bahwa kompetensi yang harus dimiliki guru adalah: Kompetensi pedagogis, Kompetensi Kepribadian, Kompetensi Sosial, dan Kompetensi Profesional. Berdasarkan kompetensi diatas maka seorang guru wajib memiliki hal berikut : mengembangkan kurikulum yang terkait dengan pembelajaran yang diampu, menyelenggarakan kegiatan pembelajaran yang mendidik, mengembangkan materi pembelajaran yang diampu secara kreatif, dan memanfaatkan teknologi informasi dan komunikasi untuk berkomunikasi dan mengembangkan diri. Berdasarkan tuntutan dan kewajiban tersebut maka seorang guru dituntut mampu menyusun modul atau bahan ajar yang inovatif dan kreatif.

Kecamatan Bandar Seikijang merupakan salah satu kecamatan yang berada di Kabupaten Pelalawan yang sebagian besar wilayahnya dilintasi oleh jalan lintas timur sumatera. Akses jalan Lintas Timur Sumatera ini merupakan jalan yang menghubungkan Kota Pekanbaru dengan Kabupaten Pelalawan. Jalan lintas timur ini banyak dilalui oleh kendaraan mulai dari kendaraan berat, kendaraan sedang, kendaraan ringan dan sepeda motor. Jalan ini merupakan daerah rawan kecelakaan. Selain itu juga ada beberapa sekolah yang persis berada di pinggir jalan tersebut salah satunya adalah TK Karya Bunda. Dari hasil survey lapangan kondisi geografis TK tersebut sangat minim dengan rambu keselamatan dan juga berada persis di tikungan sehingga titik tersebut sangat berpotensi terjadinya kecelakaan (Saleh et al., 2018).

TK menurut PP RI No. 27 Tahun 1990 tentang Pendidikan Prasekolah Bab 1 pasal 1 ayat 2 adalah salah bentuk Pendidikan Prasekolah yang menyediakan program pendidikan dini bagi anak usia empat tahun sampai memasuki pendidikan dasar. Seorang guru merupakan ujung tombak anak didiknya dalam meningkatkan kualitas pendidikan (Nurmadiah, 2015).

Guru TK sangat berperan penting karena disini seorang guru TK mendidik seorang anak yang memiliki cara berfikir yang berbeda dengan orang dewasa (Asmariani, 2016). Guru TK harus membentuk karaktek anak agar mereka memiliki pondasi akhlak dan karakter yang kuat kelaknya. Seperti halnya karaktek dalam sadar akan keselamatan berlalu lintas, harus ditanamkan sejak dini sehingga setelah dewasa masih melekat dibenaknya untuk sadar akan berlalu lintas (Nugraha \& Sudiyono, 2018).

Dalam hal ini seorang anak khususnya anak TK, yang berfikir berdasarkan pengalaman dan benda-benda yang dilihat atau benda konkret setidaknya dapat mengingatkan orang tuanya akan pentingnya keselamatan berlalu lintas (Guslinda \& Kurnia, 2018).

Berdasarkan wawancara kami dengan Ibu Jamilah yaitu Kepala Sekolah TK Karya Bunda, beliau mengatakan guru - guru TK Karya Bunda hanya berjumlah 5 orang guru satu orang sudah memiliki gelar sarjana PAUD selebihnya hanya tamat SMA, D1, D2 dan D3. Minimnya SDM yang dimiliki merupakan salah satu faktor mereka dalam hal meningkatkan kompetensi pengembangan pembelajaran salah satunya yang berkaitan dengan pembelajaran keselamatan berlalu lintas. Mereka menyadari bahwa lingkungan sekolah yang berada di jalur lintas timur, sehingga perlu dilakukan pengenalan keselamatan berlalu lintas untuk anak-anak. Selama ini pembelajaran itu belum ada diajarkan ke anak - anak, karena belum ada memiliki alat peraga 
edukatif.

Menurut Undang - Undang Guru dan Dosen Nomor 14 Tahun 2005 pasal 8 menyatakan bahwa kompetensi yang harus dimiliki guru adalah: Kompetensi pedagogis, Kompetensi Kepribadian, Kompetensi Sosial, dan Kompetensi Profesional (Ashsiddiqi, 2012). Berdasarkan kompetensi diatas maka seorang guru wajib memiliki hal berikut : mengembangkan kurikulum yang terkait dengan pembelajaran yang diampu, menyelenggarakan kegiatan pembelajaran yang mendidik, mengembangkan materi pembelajaran yang diampu secara kreatif, dan memanfaatkan teknologi informasi dan komunikasi untuk berkomunikasi dan mengembangkan diri (Zuriah et al., 2016). Berdasarkan tuntutan dan kewajiban tersebut maka seorang guru dituntut mampu menyusun modul atau bahan ajar yang inovatif dan kreatif (Mulyasa, 2003).

\section{METODE}

Metode pelaksanaan program pengabdian kepada masyarakat ini dilakukan dalam tiga tahap yaitu: (1) tahap persiapan, (2) tahap kegiatan, (3) tahap simulasi, (4) tahap evaluasi (Sujiono, 2013). Tahap perencanaan telah ditetapkan hal-hal sebagai berikut: tempat/lokasi kegiatan dipilih di TK Karya Bunda Kecamatan Sei Kijang Kabupaten Pelalawan yang terletak di pinggir jalan Lintas Timur yang termasuk daerah rawan kecelakaan. Jenis kegiatan berupa pendampingan kepada guru-guru dalam pembuatan alat peraga edukatif bertemakan keselamatan lalu lintas dan nantinya akan disimulasikan kepada siswa-siswi TK Karya Bunda sebagai media pembelajaran.

Kegiatan pengabdian pada masyarakat ini menggunakan metode dalam bentuk pendampingan melalui ceramah, demonstrasi dan Tanya jawab. Adapun tahapan-tahapn dalam pelaksanaan kegiatannya yaitu: 1 . Ceramah digunakan untuk menyampaikan pengetahuan secara umum mengenai keselamatan berlalu lintas. 2. Demonstrasi digunakan untuk memberikan keterampilan langsung mengenai proses penanganan yang berkaitan dengan permasalahan terkait keselamatan lalu lintas. 3. Tanya jawab digunakan untuk melengkapi hal-hal yang belum terakomodasi oleh kedua metode diatas. 4. Simulasi kegiatan diskusi dan pembuatan alat peraga edukatif bertemakan keselamatan lalu lintas. 5. Interaksi antara guru dan murid dalam mengimplementasikan alat permainan edukatif bertemakan keselamatan berlalu lintas (Kaltsum, 2017; Nurmadiah, 2015).

\section{HASIL DAN PEMBAHASAN}

Tim pengabdian mengajak mengajak guru untuk mengidentifikasi potensi bahaya dan resiko keselamatan di sekolah. Hasil identifikasi tersebut adalah para guru dapat mengetahui berbagai potensi bahaya dan resiko yang ada, antara lain tangga penghubung ke lantai dua dapat beresiko jatuh, lantai licin yang dapat menyebabkan jatuh dan cidera dan yang paling penting terjadi kecelakaan lalu lintas karena sekolah ini persis berada di pinggir jalan lintas provinsi yang fasilitas rambu keselamatannya sangat minim.

Setelah menjelaskan mengenai potensi bahaya dan resiko keselamatan yang ada di sekolah, selanjutnya adalah menjelaskan kepada siswa siswi mengenai rambu-rambu keselamatan sebagai bagian dari upaya pengendalian resiko. Rambu-rambu yang dijelaskan berupa rambu keselamatan lalu lintas di sekitar sekolah dan rambu keselamatan di dalam lingkungan sekolah.

Kemudian terakhir tim pengabdian melakukan kegiatan demonstrasi penerapan rambu keselamatan. Demonstrasi berupa memberikan puzzle dimana tim pengabdian berperan sebagai narrator sedangkan para guru-guru menyusun puzzle yang sudah diberikan. Berdasarkan demonstrasi ini dapat disimpulkan bahwa guru-guru sudah mengetahui rambu-rambu keselamatan yang dapat diterapkan dan juga mengerti akan arti dari rambu-rambu tersebut. 
Secara keseluruhan acara ini berlangsung dengan baik, sesuai dengan waktu yang ditentukan dan mendapatkan atensi yang cukup baik dari seluruh pihak sekolah. Adapun kendala yang ditemukan adalah dalam membuat tertib siswa siswi agar disiplin dalam duduk berbaris selama mengikuti kegiatan dan juga membuat siswa siswi tetap fokus selama berlangsungnya kegiatan. Fun learning yang diterapkan dapat membuat 75\% guru-guru benar-benar mengikuti jalnnya kegiatan dengan optimal. Kemudian guru-guru diberikan kuesioner mengenai pelaksanaan kegiatan pengabdian dengan pertanyaan sebagai berikut:

1. Pengetahuan Guru Tentang Safety Riding

a. Safety Riding adalah salah satu upaya untuk mencegah serta menurunkan kejadian kecelakaan lalu lintas

b. Safety Riding hanya dilakukan saat perjalanan jauh

c. Kewaspadaan, kesadaran, sikap dan mental merupakan konsep safety riding

d. Penerapan safety riding dilakukan secara komprehensif yaitu sebelum, saat dan setelah berkendara

e. Dalam UU No.22 Tahun 2009 diatur bahwa setiap pengendara wajib membawa SIM dan STNK

f. Helm digunakan hanya untuk melindungi dari panas dan hujan

g. Pemakaian alat keselamatan (safety apparels) dapat meminimalkan cedera saat terjadi kecelakaan

h. Keberadaan kaca spion hanya sebagai formalitas

i. Rem belakang efektif dalam membantu pengereman secara mendadak

j. Berkendara melawan arus dapat menyebabkan kecelakaan

k. Service pada sepeda motor hanya dilakukan saat ditemukan kerusakan pada bagian motor

1. Sepeda motor berjalan di lajur kiri, pengguna lajur kanan hanya untuk mendahului

$\mathrm{m}$. SIM, STNK dan mengenakan helm standar adalah komponen penting yang diwajibkan pengendara kendaraan bermotor roda dua

2. Sikap Guru Terhadap Safety Riding

a. Safety Riding dapat mencegah terjadinya kecelakaan

b. Anda melakukan safety riding meskipun tidak ada bahaya yang mengancam terjadinya kecelakaan

c. Ketika akan melakukan perjalanan dekat, anda tidak perlu melakukan pemeriksaan kendaraan

d. Anda boleh membawa penumpang lebih dari 1 orang dewasa

e. Demi keamanan, anda selalu membawa SIM C dan STNK saat berkendara

f. Ketika hendak membelok sebaiknya terlebih dahulu nenyalakan lampu sein

g. Ketika jalanan sepi, anda boleh mengendarai sambil memegang handphone

h. Sebaiknya melakuakan service rutin untuk mengetahui kondisi sepeda motor agar tetap aman

3. Persepsi Guru Tentang Safety Riding

a. Setiap pengendara harus mematuhi hukum dan undang-undang yang berlaku

b. Menjalankan kendaraan dengan kecepatan tinggi berpotensi kecelakaan

c. Anda harus selalu berhati-hati dan waspada ketika berkendara

d. Menurut anda, pengecekan kendaraan sebelum berkendara wajib dilakukan

e. Menurut anda, ketika berkendara saat membonceng anak usia dini harus memakai perlengkapan seperti helm, jaket, masker, sarung tangan dan sepatu serta membawa SIM dan STNK

f. Menurut anda, selalu mengecek kaca spion adalah salah satu cara untuk menghindari kecelakaan

g. Menurut anda, menerima telepon pada saat berkendara tidak mengganggu konsentrasi 
4. Peran Guru kepada siswa dalam penerapan safety riding

a. Apakah anda menerapkan budaya keselamatan berlalu lintas kepada siswa didik anda

b. Apakah anda pernah menggunakan alat peraga edukatif bertemakan keselamatan lalu lintas kepada siswa didik anda

c. Apakah anda mengajarkan kepada siswa didik seputar pengenalan rambu-rambu saat berkendara

d. Apakah anda pernah memberikan penjelasan rambu-rambu kepada siswa didik anda

e. Jika siswa didik anda pulang sekolah apakah anda memberikan nasehat mengenai keselamatan lalu lintas setidaknya berhati-hati di jalan

f. Pentingkah menjadi role model dalam penerapan safety riding untuk siswa didik anda

Adapun hasil dari kuesioner tersebut dapat dilihat pada gambar berikut ini:

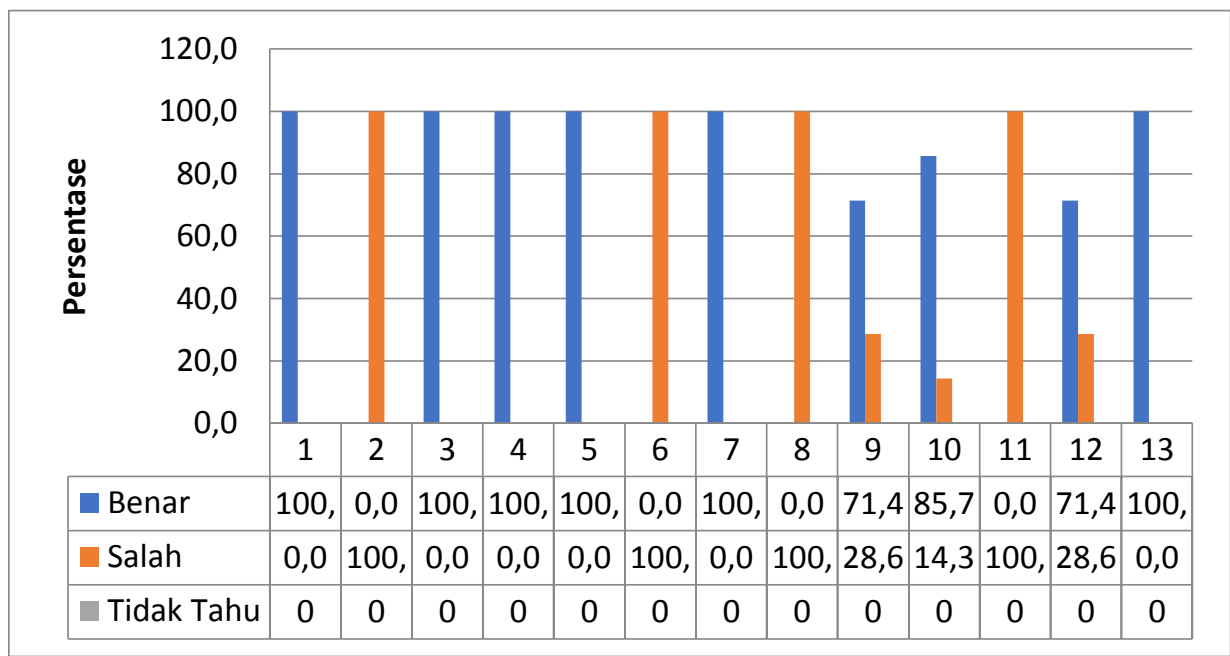

Gambar 1. Pengetahuan Guru Tentang Safety riding

\begin{tabular}{|c|c|c|c|c|c|c|c|c|c|}
\hline \multirow{6}{*}{ 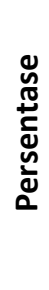 } & \multirow{2}{*}{\multicolumn{9}{|c|}{$\begin{array}{l}120,0 \\
100,0\end{array}$}} \\
\hline & \multicolumn{5}{|l|}{80,0} & & & & \\
\hline & \multicolumn{9}{|l|}{60,0} \\
\hline & 40,0 & & & & & & & & \\
\hline & 20,0 & & & & & & & & \\
\hline & 0,0 & 1 & 2 & 3 & 4 & 5 & 6 & 7 & 8 \\
\hline \multicolumn{2}{|c|}{ Sangat Setuju } & 100,0 & 57,1 & 0,0 & 0,0 & 85,7 & 85,7 & 0,0 & 85,7 \\
\hline \multicolumn{2}{|c|}{ Setuju } & 0,0 & 42,9 & 0,0 & 14,3 & 14,3 & 14,3 & 0,0 & 14,3 \\
\hline \multicolumn{2}{|c|}{ Ragu-Ragu } & 0,0 & 0,0 & 14,3 & 28,6 & 0,0 & 0,0 & 0,0 & 0,0 \\
\hline \multicolumn{2}{|c|}{ Tidak Setuju } & 0,0 & 0,0 & 85,7 & 57,1 & 0,0 & 0,0 & 57,1 & 0,0 \\
\hline \multicolumn{2}{|c|}{ Sangat Tdk Setuju } & 0,0 & 0,0 & 0,0 & 0,0 & 0,0 & 0,0 & 42,9 & 0,0 \\
\hline
\end{tabular}

Gambar 2. Sikap Guru Terhadap Safety riding 


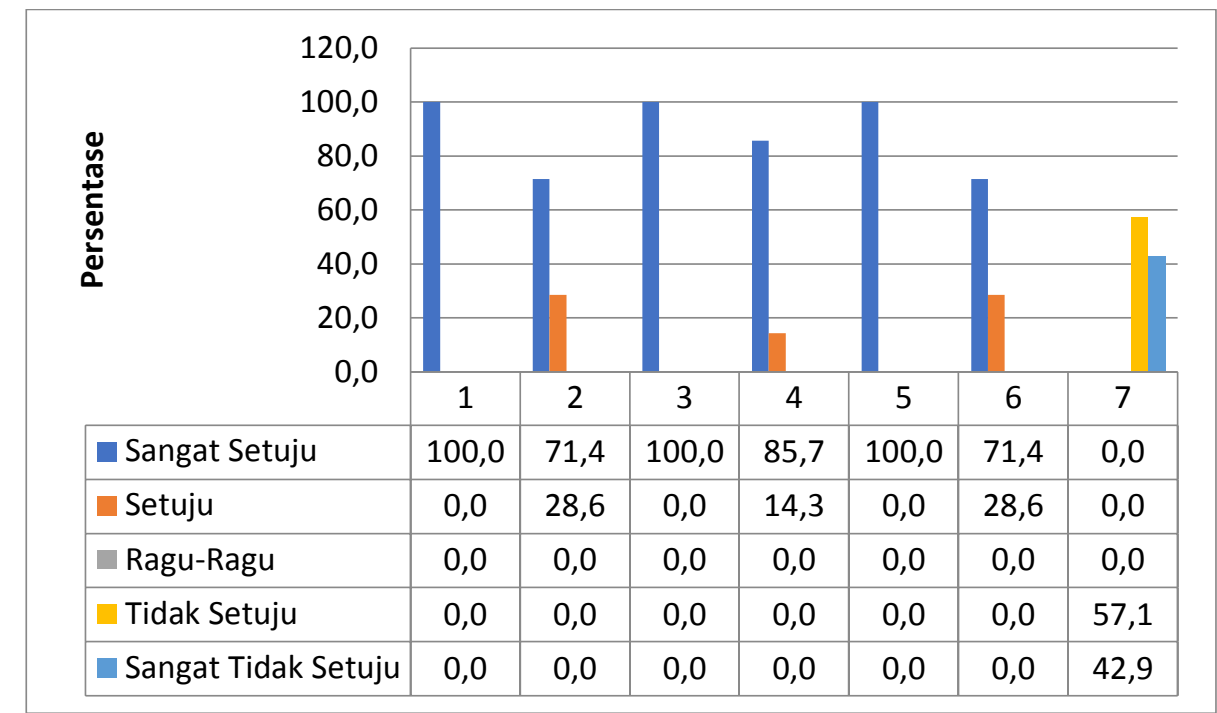

Gambar 3. Persepsi Guru Terhadap Safety riding

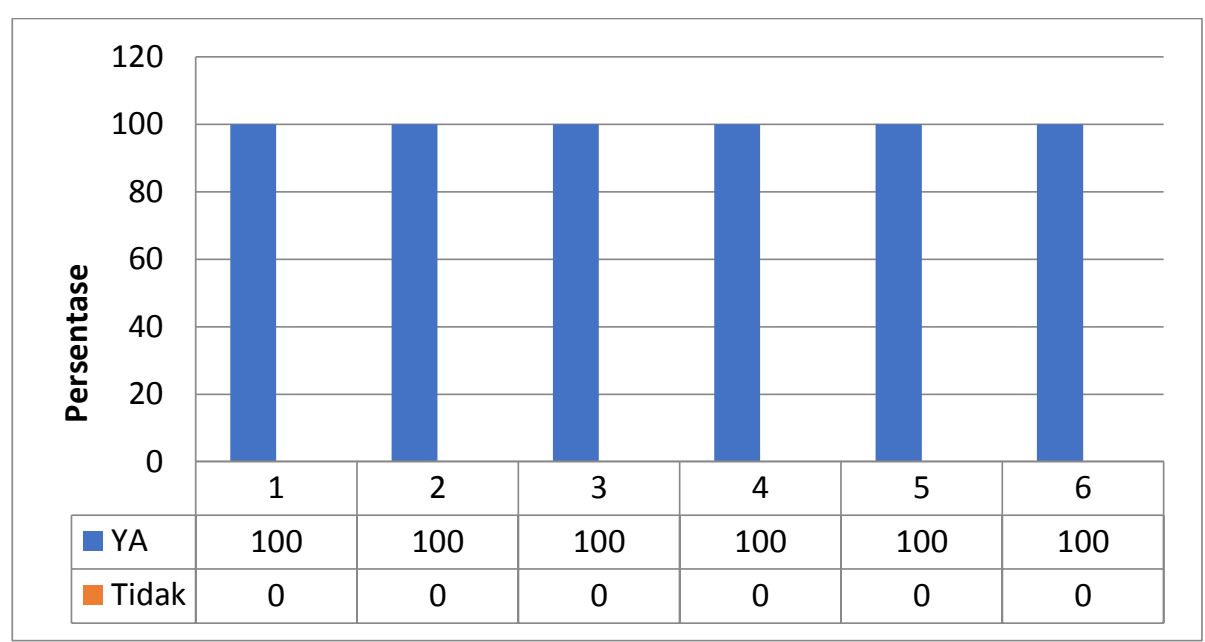

Gambar 4. Peran Guru Kepada Siswa Dalam Penerapan Safety riding
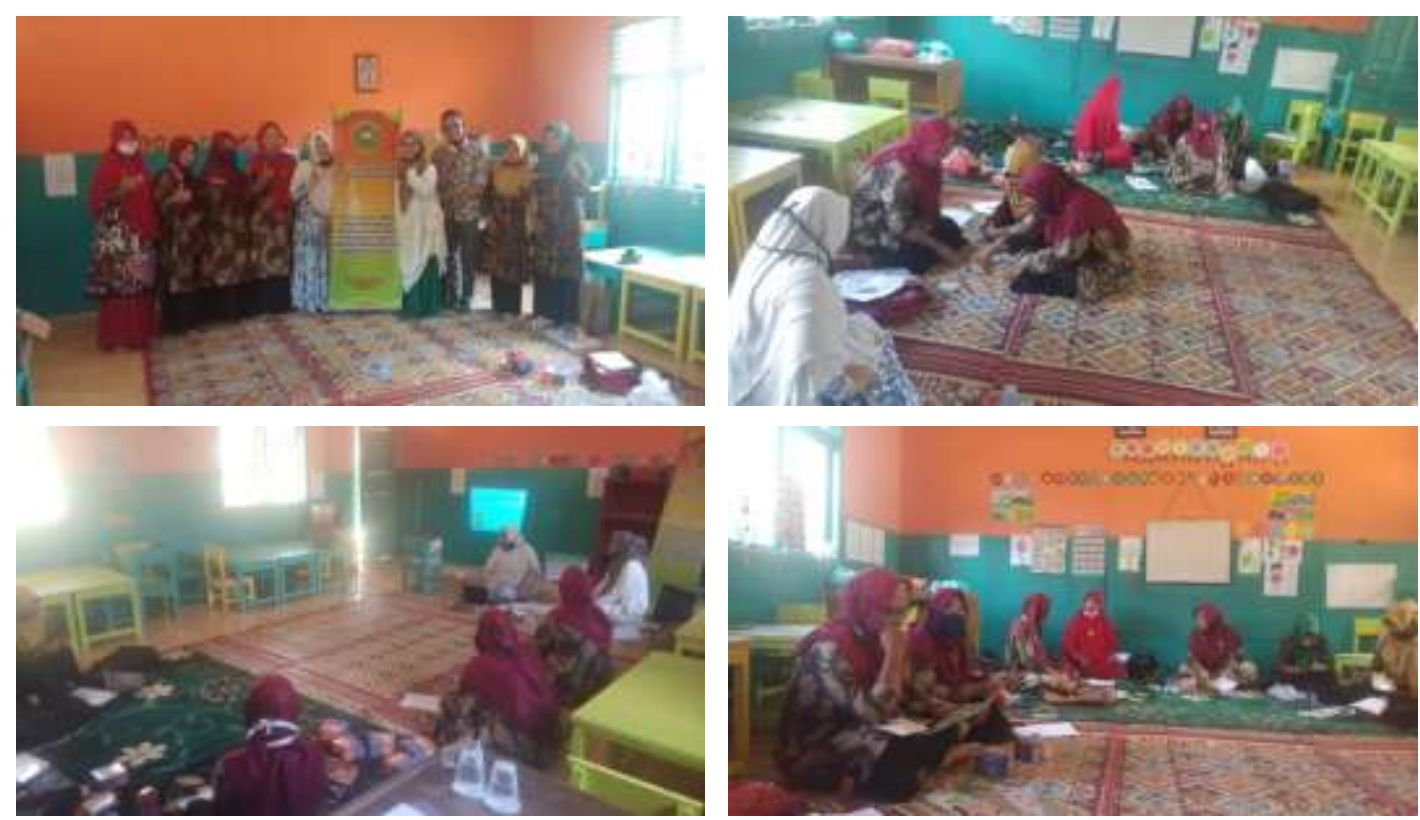

Gambar 5. Dokumentasi Kegiatan Pengabdian 


\section{KESIMPULAN}

Beberapa kesimpulan dari kegiatan pengabdian masyarakat ini adalah para guru mampu mengidentifikasi potensi bahaya dan resiko keselamatan yang ada di lingkungan sekolah serta mampu mengetahui tentang arti dan fungsi dari masing-masing rambu keselamatan yang telah dijelaskan. Diharapkan ada kegiatan pendidikan keselamatan lanjutan yang sasarannya lebih luas meliputi penerapan keselamatan lalu lintas melalui media pembelajaran alat permainan yang edukatif karena dapat mewujudkan kekompakan siswa-siswa dan guru.

Pemahaman anak pada setiap aspek keselamatan diri mungkin saja dibentuk oleh lingkungan social disekitarnya, terutama orang tua dan sekolah. Orang tua perlu lebih berperan aktif dengan mengajarkan secara langsung kepad anak berbagai potensi bahaya berikut cara-cara mengatasinya.

\section{UCAPAN TERIMA KASIH}

Penulis mengucapkan terima kasih kepada Lembaga Penelitian dan Pengabdian Masyarakat (LPPM) Universitas Lancang Kuning yang telah memberi dukungan financial terhadap pengabdian ini.

\section{DAFTAR PUSTAKA}

Ashsiddiqi, M. H. (2012). Kompetensi Sosial Guru dalam Pembelajaran dan Pengembangannya. TA'DIB, XVII(01), 61-67.

Asmariani, A. (2016). Konsep Media Pembelajaran Paud. Al-Afkar, V(1), 25-42.

Guslinda, G., \& Kurnia, R. (2018). Media Pembelajaran Anak Usia Dini. CV. Jakad Publishing.

Kaltsum, H. U. (2017). Pemanfaatan Alat Peraga Edukatif Sebagai Media Pembelajaran Bahasa Inggris Sekolah Dasar. URECOL (The 6th University Research Colloquium), 19-24.

Mulyasa, M. (2003). Kurikulum Berbasis Kompetensi Konsep: Karakteristik dan Implementasi. PT. Remaja Rosdakarya.

Nugraha, D. A., \& Sudiyono. (2018). Pelatihan dan Pendampingan Pembuatan Media Pembelajaran Interaktif Menggunakan Autoplay Media Studio Bagi Guru-Guru SDN Merjosari 1. Terap. Abdimas, 3(2), 182-187.

Nurmadiah, N. (2015). Strategi Pembelajaran Anak Usia Dini. Al-Afkar, III(1), 1-28.

Saleh, A., Anggraini, M., \& Efastri, S, M. (2018). Implementasi Keselamatan Lalu Lintas Pada Anak Usia Dini Dengan Metode Pendekatan Pembelajaran Kooperatif Tipe Role Playing. Dinamisia, 2(1), 42-46.

Sujiono, Y. N. (2013). Konsep Dasar Pendidikan Anak Usia Dini. PT. Indeks.

Zuriah, N., Sunaryo, H., \& Yusuf, N. (2016). IbM Guru Dalam Pengembangan Bahan Ajar Kreatif Inovatif Berbasis Potensi Lokal. Dedikasi, 13, 39-49. 